NBER WORKING PAPER SERIES

STOCK PRICES AND ECONOMIC NEWS

Douglas K. Pearce

V. Vance Roley

Working Paper No. 1296

NATIONAL BUREAU OF ECONOMIC RESEARCH

1050 Massachusetts Avenue

Cambridge, MA 02138

March 1984

The research reported here is part of the NBER's research program in Financial Markets and Monetary Economics. Any opinions expressed are those of the authors and not those of the National Bureau of Economic Research. 
NBER Working Paper 非1296

March 1984

\title{
Stock Prices and Economic News
}

\begin{abstract}
This paper examines the daily response of stock prices to announcements about the money supply, inflation, real economic activity, and the discount rate. Except for the discount rate, survey data on market participants' expectations of these announcements are used to identify the unexpected component of the announcements in order to test the efficient markets hypothesis that only the unexpected part of any announcement, the surprise, moves stock prices. The empirical results support this hypothesis and indicate further that surprises related to monetary policy significantly affect stock prices. There is only limited evidence of an impact from inflation surprises and no evidence of an impact from real activity surprises on the announcement days. There is also only weak evidence of stock price responses to surprises beyond the announcement day.
\end{abstract}

Douglas K. Pearce Department of Economics University of Missouri-Columbia Columbia, MO 65201 (314) 882-6655

V. Vance Roley Department of Finance DJ-10 Graduate School of Business Admin. University of Washington Seattle, WA 98195 (206) 545-7476 


\section{STOCK PRICES AND ECONOMIC NEWS}

\section{INTRODUCTION}

The interpretation of daily stock price movements as reactions to announcements of economic events is commonplace in the media. Commentators often report that stock prices fell because of "disappointing unemployment figures" or rose because of "encouraging news on the inflation front." There has been, however, little systematic evidence on the quantitative impact on stock prices of such announcements. One obstacle to research in this ârea is the difficulty in distinguishing that part of an announcement which was unanticipated. According to the efficient markets hypothesis, security prices should only respond to the unexpected part of any announcement, i.e., that part which is truly news, since the expected part of the announcement should already be embedded in stock prices. In addition, this hypothesis maintains that the full response of stock prices to news will occur essentially immediately. This paper employs survey data on market participants' expectations of certain economic announcements to investigate whether the evidence supports the efficient markets view.

Previous studies of the effects of economic announcements on stock prices generally provide little direct evidence on the validity of the efficient markets theory. While Fama et al. (1969) conclude that the information contained in stock splits is rapidly incorporated into stock prices, they cannot distinguish expected from unexpected splits and their use of monthly data prevents them from investigating the precise timing within which information is processed. Waud (1970) finds a significant and immediate negative response of stock prices to discount rate changes but he does not test whether the complete response takes more than one day. If Castanias 
(1979) reports that the variance of stock prices rises around the days of most economic news events which he interprets as a reflection of new information appearing. Again, however, expected and unexpected announcements are not differentiated since Castanias simply uses dummy variables for the days of the announcements. Schwert (1981) examines the stock market reaction to the monthly CPI inflation rate announcement and does use a measure of unexpected inflation rather than just the announced rate. Schwert's results contradict the efficient markets hypothesis since they imply a slow adjustment of share prices to new information on inflation.2/ On the other hand, Pearce and Roley (1983) find that the response of stock prices to the weekly money stock announcement is consistent with the efficient markets theory since only the unexpected money stock change had a significant effect and this effect was complete within the trading day after the announcement. 3 /

This paper extends our previous study by including measures of agents expectations of monthly inflation and real activity announcements along with anticipated money announcements. Fortunately, survey data exist on market participants' expectations of these economic announcements so that direct measures of the unexpected changes or surprises can be constructed. These data run from September 1977 through October 1982 thereby allowing tests of the interesting question of whether the stock market's reactions to economic news changed after the Federal Reserve altered its operating procedure in October 1979.

Section II outlines the theoretical framework of the study. Section III describes the data along with tests of the rationality of the expectations variables. Section IV presents the empirical results of market efficiency tests while the final section gives the main conclusions. II. Theoretical Framework 
In this section, the specifications used to estimate the impact of new economic information on stock prices is presented. Following the specification of the model, possible links between stock prices and new information about the money stock, inflation, output, and the Federal Reserve's discount rate are discussed.

A. The Model

In order to estimate the impact of new economic information on stock prices and to test the main propositions of the efficient markets hypothesis, the following model is used:4]

$$
\Delta S P_{t}=a+\underline{x}_{t}{ }^{u} \cdot \underline{b}+\underline{x}_{t} e \cdot \underline{c}+\sum_{i=1}^{m} \underline{x}_{t-i} u \cdot \underline{d}_{i}+e_{t}
$$

where $\Delta S P_{t}=$ change in stock prices from the close of trading on day $t-1$ to the close of trading on day $t$, in percent

$\underline{x}_{t} \mathbf{u}=1 \times k$ vector of unanticipated components of economic data announcements, computed as the difference between announced values, $\underline{x}_{t}{ }^{a}$, and expected values, $\underline{x}_{t}{ }^{e}$

$\underline{x}_{t} e=1 \times k$ vector of expected announced values of economic data based on information known as of the close of trading on day $t-1$

$\underline{x}_{t-i^{u}}=1 \times k$ vector of surprises which occurred $i$ days prior to day $t$

$e_{t}=$ random error term uncorrelated with information known as of the close of trading on day $t-1$

$a, \underline{b}, \underline{c}, \underline{d}_{i}=$ scalar and $k x 1$ vectors of parameters.

If expectations are rational, then

$$
\underline{x}_{t} e=E\left(\underline{x}_{t}{ }^{a} \mid \Omega_{t-1}\right)
$$

where $\underline{x t}^{a}=1 x k$ vector of announced values of economic data

$\Omega_{t-1}=$ information set as of the close of trading on day $t-1$ so that $\left(\underline{x}_{t^{a}}^{a} \underline{x t}_{t}\right)$ is uncorrelated with $\Omega_{t-1}$.

The efficient markets hypothesis specifies that each element of $c$ should equal zero since the previous day's stock prices, $\mathrm{SP}_{\mathrm{t}-1}$, should reflect all known information, $\Omega_{t-1}$. Furthermore, this theory implies that each element of $\mathrm{d} i$ hould equal zero since nonzero elements in di would indicate that stock 
prices only slowly adjust to economic news. Thus, under the maintained hypothesis that that market is efficient, the model becomes

$$
\Delta S P_{t}=a+\underline{x} t^{u} \underline{b}+e t
$$

and the data should not reject equation (3) in favor of equation (1). The remainder of this section discusses the elements of $\underline{x} t^{u}$ considered in this paper in terms of their potential effects on stock prices.

B. Impact of Money Stock Surprises

A number of recent studies--including those by Grossman (1981), Urich and Wachtel (1981), Roley (1982), Cornell (1983a) and Pearce and Roley (1983)--have examined the impact of the weekly money stock announcement on security returns. The consensus finding is that unexpectedly high money growth is associated with higher interest rates and lower stock prices.5/ There are, however, two competing interpretations of this result. First, agents may believe that the Federal Reserve will react to unexpectedly high money growth by quickly moving to a more restrictive monetary policy which would lead to higher interest rates. The anticipation of higher rates in the near future causes agents to sell securities immediately, forcing interest rates upward. Higher interest rates then lead to lower stock prices, assuming investors view these assets as substitutes.6/ In this view, unexpectedly high money growth causes real interest rates to rise. The second interpretation is that agents revise upwards their expectations of inflation when a positive money announcement surprise occurs. Higher expected inflation both pushes up nominal interest rates through the Fisher effect and pulls down stock prices if inflation has a negative effect on real, after-tax corporate profits (e.g., Feldstein (1980) and Summers (1981)). 


\section{Impact of Inflation Surprises}

Another much publicized economic announcement is the monthly report on the rate of inflation measured in the previous month. $\exists$ Inflation surprises may have both direct and indirect effects on stock prices.8/ A direct effect could emerge if a positive surprise in announced inflation induces agents to raise their level of expected inflation. Higher expected inflation, as mentioned above, could then depress stock prices.

A second direct channel by which inflation surprises may affect stock prices occurs if agents believe that policymakers react to inflation news. Unexpectedly high inflation may lead to more restrictive policies which in turn lead to reduced cash flows for firms and lower stock prices. Similar to this channel, if a positive inflation surprise causes agents to revise upward their assessment of future money demand, higher interest rates and lower stock prices may result if agents further expect the Federal Reserve to maintain its previous monetary growth objectives. In any event, all of these potential links suggest that stock prices may be negatively related to surprises in announced measures of inflation.

D. Impact of Output Surprises

A third economic announcement considered is the monthly report on real activity in the previous month. Announced increases in real economic activity, if greater than expected, may increase agents' expectations of future growth. Forecasts of higher economic growth should make stocks more attractive and thus cause an immediate jump in share prices.

Alternatively, announced output surprises may again cause agents to forecast more restrictive policy in the future if such surprises are correlated with future inflation or money growth. In this case, if the public perceives that the Federal Reserve will not accommodate these increases, 
interest rates may rise and stock prices may fall. As a result, the likely impact of output surprises on stock prices cannot be determined a priori.

E. Discount Rate Changes

The fourth economic announcement is a change in the Federal Reserve's discount rate. Unlike the other three types of announcements, a survey measure of expected discount rate changes is not available. Empirical evidence discussed in the next section, however, indicates that it is reasonable to view discount rate changes as unanticipated, at least in terms of timing and perhaps also in terms of magnitude.

Waud (1970), among others, argued that discount rate changes have announcement effects concerning monetary policy. In a recent study by Roley and Troll (1984), empirical evidence suggested that these announcement effects are associated with changes in short-run monetary policy objectives, and not changes in trend money growth. An increase in the discount rate, for example, corresponds to a short-run objective of returning to the implied long-run money growth target more quickly. As a result, market interest rates rise, reflecting reduced short-run money growth. Since long-run money growth objectives are unchanged, there are no offsetting effects due to possible reductions in expected future inflation. Thus, if stock prices are affected by discount rate increases, they should fall in response to the rise in market interest rates.

The information content of discount rate changes also was found by Roley and Tro11 (1984) to depend on the type of operating procedure adopted by the Federal Reserve. Under the reserves-aggregate procedure utilized during the three years following October 6, 1979, discount rate changes revealed new information about short-run policy objectives as described above. Under the federal funds rate procedure used prior to October 1979, however, significant 
information was not revealed by discount rate changes. In this latter case, movements in the federal funds rate conveyed changes in short-run objectives directly. Thus, the response of stock prices may be different in the pre- and post-October 1979 periods.

To summarize, four economic news events are considered: announcements on the money stock, inflation, real activity, and the discount rate. As described above, unanticipated increases in money, inflation, and the discount rate may be viewed as bad news for the stock market and thus should be followed by a fall in stock prices. Unexpectedly strong real growth may be viewed as good news with stock prices rising as a result, unless future policy is assessed as being more restrictive. If the stock market is efficient, any response will be essentially immediate.

III. DATA

The data for stock prices, economic data announcements, and expected values of economic data announcements are discussed in this section. Because of the important role of expectations, the expectations data are examined in detail. The sample period used in this paper begins on September 29, 1977 , and ends on October 15, 1982. The starting date corresponds to the availability of the survey data used to represent expectations, and the ending date is around the time that the Federal Reserve de-emphasized the reserveaggregate monetary control procedure.

A. Stock Prices

To estimate the response of stock prices to new information, daily changes in an index of closing stock prices are used. For economic announcements occurring either before or while the stock market is open, the previous business day's closing prices are subtracted from the closing prices on that day. For announcements occurring after the stock market is closed, 
that day's closing stock prices are subtracted from the next business day's closing prices. These measured changes give the market ample opportunity to reflect the receipt of new information. The possibility that the effect of new information persists beyond one day is, however, also tested below. The particular stock index employed is the Standard and Poor's 500 index (S\&P500). Thus, the dependent variable is the daily percentage change of closing values of the S\&P500.9]

B. Announcement Data

The money stock data consist of announced weekly changes in the narrowly defined money stock as reported in the Federal Reserve's H.6 release. A reported change corresponds to the estimate of the level of the money stock for the statement week ending on Wednesday of the previous calendar week minus the revised estimate of the previously reported level of the money stock. Until January 31,1980 , the data used here correspond to announced changes in "old MI" on Thursdays at 4:10 p.m. Since then, the announcements have been made on Fridays at 4:10 p.m. For the period, the data employed are those for M1-B, and more recently, MI, where the definition of the latter aggregate is equivalent to that of $M 1-B .10 /$

The inflation data correspond to percentage changes in the consumer price index (CPI) and the producer price index (PPI), as initially announced by the Bureau of Labor Statistics. In each case, values were released monthly on various days of the week, and they provide information about inflation during the preceding month.

Data on industrial production (IP) and the unemployment rate (RU) are used to represent real economic activity. The industrial production data correspond to the percentage changes announced initially by the Federal Reserve. Similarly, the Bureau of Labor Statistics' initial release of the 
unemployment rate is used. While data on the industrial production index were released on various days of the week, the unemployment rate was usually released on the first Friday of each month.

Discount rate changes correspond to the initial announcement of the Board of Governors of the Federal Reserve System regarding a new level of the discount rate. In some instances, the change in the discount rate did not become effective on the same day for all Federal Reserve banks. However, differentials in the discount rate did not usually persist beyond one business day. In the post-0ctober 1979 period, announced changes in the surcharge rate also are considered.

C. Expectations Data

To estimate the impact of economic news, the efficient markets hypothesis implies that only the unanticipated components of economic announcements should be used. Some measure of the market's expectation must be obtained to form these unanticipated components. A convenient source of these expectations data is that provided by Money Market Services, Inc., which surveys about 60 money market participants each week.11/ Before February 8 , 1980, surveys were conducted twice each week, on Tuesdays and Thursdays. The Thursday surveys were conducted to obtain a revised estimate of the money announcement. Other prospective announcements were not generally resurveyed on Thursday. After February 8, 1980, the survey was conducted only on Tuesdays. Following Roley (1983), the survey data were adjusted in both periods in an effort to incorporate new information available from the time of the survey to the time of the respective economic announcement. 12/ Because the adjusted data did not yield significantly different empirical results, however, only the results using the unadjusted survey data are reported here. 
With the exception of discount rate announcements, survey data are available for all of the announcements considered here. For the discount rate, the entire announced change is assumed to be unanticipated. Discount rate changes have, however, sometimes been interpreted as merely reflecting past movements in short-term market interest rates (e.g., Lombra and Torto. (1977)). The underlying hypothesis in this case is that the discount rate is changed to realign it with the Federal funds rate. Roley and Iroll (1984) examine this hypothesis by regressing daily movements in the discount rate-which are zero unless a discount rate change is announced--on the cumulative change in the federal funds rate since the last discount rate announcement. In both the pre- and post-0ctober 1979 periods, less than 2 percent of the variation in discount rate changes is explained. Thus, information about past values of the federal funds rate has very limited usefulness in predicting the exact timing, and perhaps also the magnitude, of discount rate changes.

To examine the expectations data for the other economic announcements, three tests are performed. First, the unbiasedness of the survey data is examined in Table 1. If the survey data are rational, no systematic bias should be evident. The test results indicate that unbiasedness cannot be rejected at the 5 percent level of significance for all of the data except those for expected values of industrial production announcements. In this latter case, the survey measure is downward biased in absolute value, as reflected by the estimated value of $f_{1} .13 /$

Second, the efficiency of the survey expectations measure is tested in Table 2. Following Modigliani and Shiller (1973), the basic notion behind this concept is that if announced data are generated by an autoregressive process, the market's expectation should be generated by the same process. Thus, coefficients on lagged values of announced data in a regression with the 
unanticipated component of an announcement should be insignificantly different from zero.14/ As indicated in the table, the null hypothesis cannot be rejected at low significance levels for any of the survey data.15

Finally, the forecast performances of the survey data are compared to those of autoregressive models in Table 3. In estimating the autoregressive models, the number of lagged values was determined by the statistical significance of the lag coefficients and the properties of the residuals. Because the autoregressive models are estimated over the entire forecast period, their root-mean-square errors (RMSE) are actually understated. Nevertheless, the survey data have lower root-mean-square errors than the simple autoregressive models.16/

As a whole, the survey data used here exhibit desirable properties, especially in comparison to other survey data.17/ Thus, these data enable direct tests of the efficient markets hypothesis. IV. RESPONSE OF STOCR PRICES: EMPIRICAL RESULTS

\section{A. Initial Responses to Announcements}

Using the expectations data described above, the impact of both anticipated and unanticipated components of economic announcements on the daily percentage change in stock prices is estimated. The most general specification is represented by equation (1). Various subcases of equation (1)--determined by the constraints $\underline{c}=\underline{0}$ or $\underline{d_{i}}=\underline{0}$--are estimated over the two subsamples discussed previously.

The estimated response of stock prices to announcement surprises is presented in Table 4. Due to their lack of statistical significance, the reported equations do not include day-of-the-week dummy variables. In both the pre- and post-0ctober 1979 subsamples, the hypothesis that all day-of-theweek effects are equal could not be rejected at the 5 percent level of 
significance.18/ Moreover, the presence or absence of day-of-the-week dummy variables had virtually no effect on the empirical results reported below.

In the pre-October 1979 period, the estimation results indicate that only money and PPI surprises affect stock prices significantly. In both cases, the response is negative as anticipated. The estimated coefficients imply that a $\$ 1$ billion money surprise causes stock prices to fall by about 0.9 percent and that a 1 percentage point surprise in the PPI results in a decline in stock prices of about 1.09 percent. Surprises in announced values of the CPI, industrial production, the unemployment rate, and the discount rate are statistically unrelated to stock prices during this period, at least on announcement days.19/

In the post-October 1979 period, the impact of money surprises is again statistically significant, but the impact of PPI surprises is not significantly different from zero. During this subsample, however, the impact of changes in the basic discount rate is significant at the 5 percent level, and the effect of changes in the surcharge rate is significant at the 10 percent level. No other announcement surprises are estimated to have significant effects during this period.

The statistical significance of various subsets of coefficients is examined in the lower half of Table 4. In the first row, the hypothesis that all response coefficients equal zero is tested for the two subsamples. This hypothesis cannot be rejected at the 10 percent level of significance in the pre-0ctober 1979 subsample, but it can be rejected at less than the 1 percent level in the post-0ctober 1979 subsample. In the second row, the significance of inflation and real activity surprises are examined as a group. The hypothesis that this set of variables has no impact on stock prices cannot be rejected at the 10 percent level in each period. In contrast, the hypothesis 
that money and discount rate surprises have insignificant effects, as reported in the third row, can be rejected at less than the 1 percent level in each subsample. As a whole, these results suggest that surprises related directly to monetary policy have the main effects on stock prices, at least on the days of the announcements.

The last row in Table 4 examines the response of stock prices to anticipated announced values of economic data. Under the efficient markets hypothesis, these expectations should already be reflected by stock prices and therefore should not further affect daily changes. In both the pre- and postOctober 1979 periods, this hypothesis cannot be rejected at the 10 percent level of significance. Thus, the results reported in the table are consistent with the efficient markets hypothesis.

One final issue, not reported in Table 4, also was empirically examined. In particular, the equality of stock price responses across the pre- and postOctober 1979 periods were tested. Consistent with the results reported by Pearce and Roley (1983), no significant difference between either sets of coefficients or individual responses was found across periods.20/ This result again is in sharp contrast to the significant change in the response of both short- and long-term interest rates to new information following the Federal Reserve's adoption of the reserves-aggregate operation procedure on October 6 , 1979 (see, for example, Roley and Troll (1983) and Cornell (1983a)).

B. Speed of Stock Price Adjustment

In order to investigate whether the effect of new information on stock prices persists beyond one business day, the model was reestimated using four alternative dependent variables.21/ For example, the first ( $\triangle S P 1$ ) is the percentage change in the S\&P500 from the first closing quotes to the closing quotes in the subsequent day. The second ( $\triangle S P 2)$ is the percentage change in 
stock prices in the next day calculated in the same manner with SP3 and SP4 having corresponding definitions. Thus, the response of stock prices over the four business days following an economic announcement is examined.

The estimated models for each subsample are presented in Table 5. In the pre-0ctober 1979 subsample, only one out of a possible 24 response coefficients is statistically significant at the 5 percent level. In particular, the PPI surprise is estimated to affect stock prices significantly in the fourth day following its announcement. The stock price response also is estimated to offset the effect on the announcement day, which is reported in Table 4.

In the post-0ctober 1979 subsample, four out of a possible 28 response coefficients are statistically significant at the 5 percent level. In the day following an announced change in the discount rate, stock prices are estimated to continue to fall (rise) for a discount rate increase (decrease). For the surcharge rate, however, the initial announcement effect is offset in the subsequent business day. The results also suggest that positive (negative) industrial production surprises have significantly positive (negative) effects on stock prices in the second day following their announcement. Finally, in the fourth day following an announcement of a change in the surcharge, the estimated stock price response is again significantly negative.

Because of the number of coefficients estimated in Table 5, the statistical significance of any small set of coefficients should be interpreted cautiously. In particular, only 5 out of a possible 52 estimated coefficients are statistically significant at either the 5 or 10 percent levels, which may be expected even if no actual relationship exists. Thus, the empirical results in Table 5 do not provide strong evidence that stock prices in some instances respond slowly or even move to offset initial 
announcement effects. It is interesting to note, nevertheless, that in contrast to Schwert (1981) CPI surprises are not found to have significant effects on stock prices in days following announcements. Also, the response to money surprises is estimated to be complete within the day of an announcement, which is consistent with the results reported by Pearce and Roley (1983) using the Dow Jones Industrial Average.

V. SUMMARY AND CONCLUSIONS

This paper has examined the daily response of stock prices to announcements of the narrowly defined money stock, the CPI, the PPI, the unemployment rate, industrial production, and the Federal Reserve's discount rate. To represent the new information provided by an announcement, a measure of the market's expectation is used. Several conclusions follow from this empirical investigation. First, new information related directly to monetary policy significantly affects stock prices. In particular, money announcement surprises have a significantly negative effect on stock prices in the sample period beginning in September 1977 and ending in October 1982. In the subsample beginning in October 1979 , discount rate changes also have significant effects. Second, only limited evidence supports the view that either inflation or real economic activity surprises affect stock prices. In the pre-October 1979 subsample, PPI surprises have significant effects on the day of an announcement, but they are estimated to be offset by the end of one week. In both subsamples, surprises in announced levels of real economic activity have no significant impact on stock prices on the day of an announcement. Third, the empirical results indicate that anticipated components of economic announcements do not significantly affect daily stock price movements, which is consistent with the efficient markets hypothesis. Finally, some evidence is presented which suggests that the response of stock 
prices to new information may persist beyond the announcement day, although for most economic announcements this is not found. 


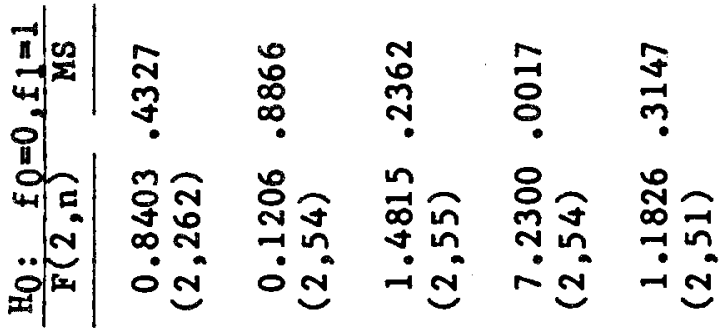

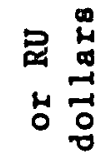

芦出

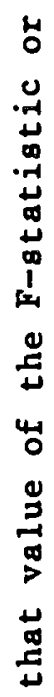

我怘

a

$\exists$

हैं हैं

告

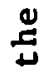

出

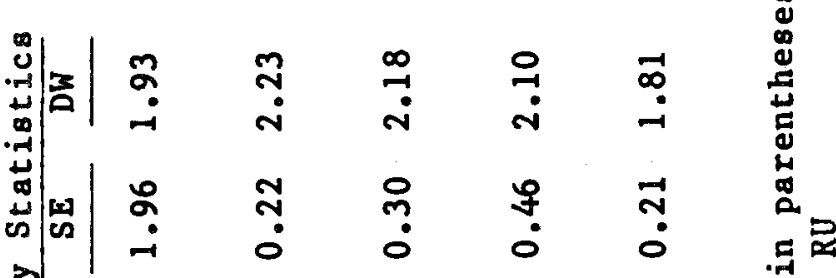

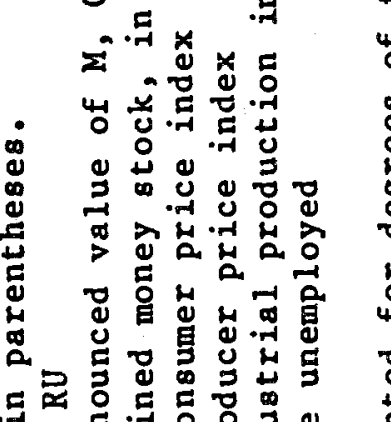

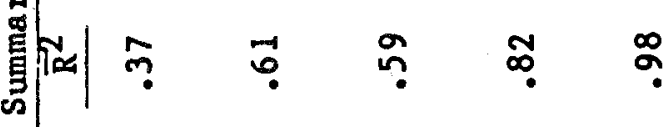

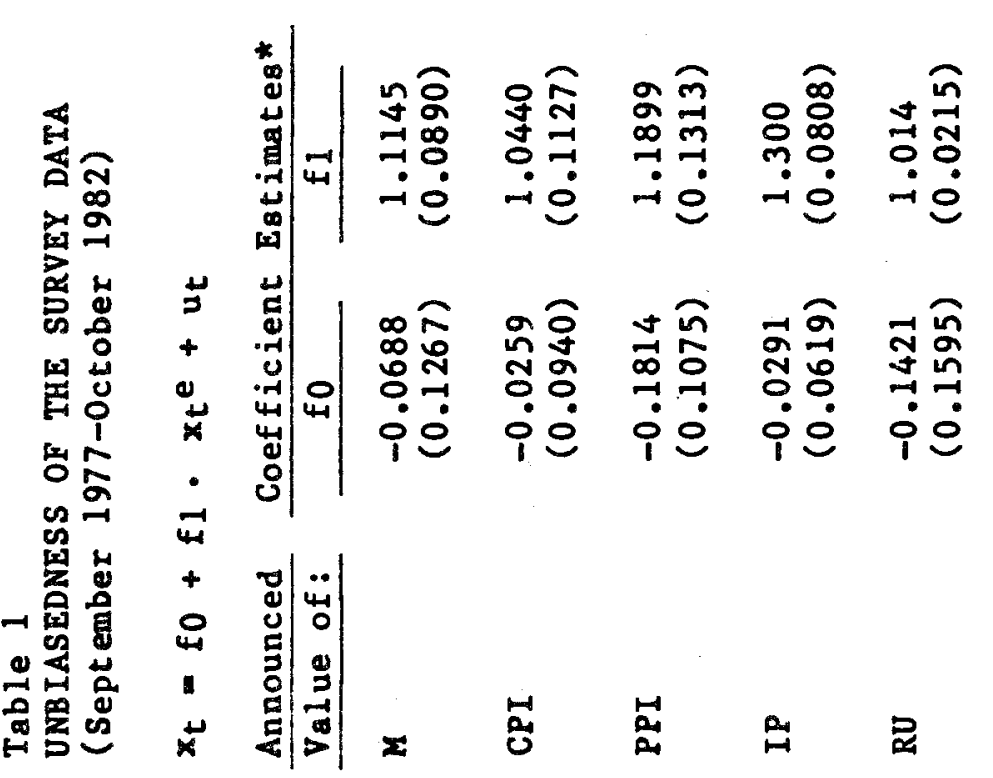
告

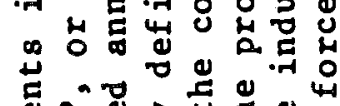

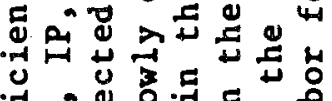

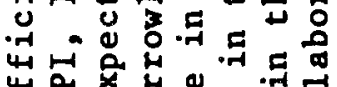

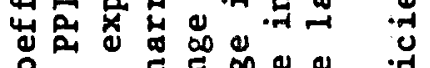



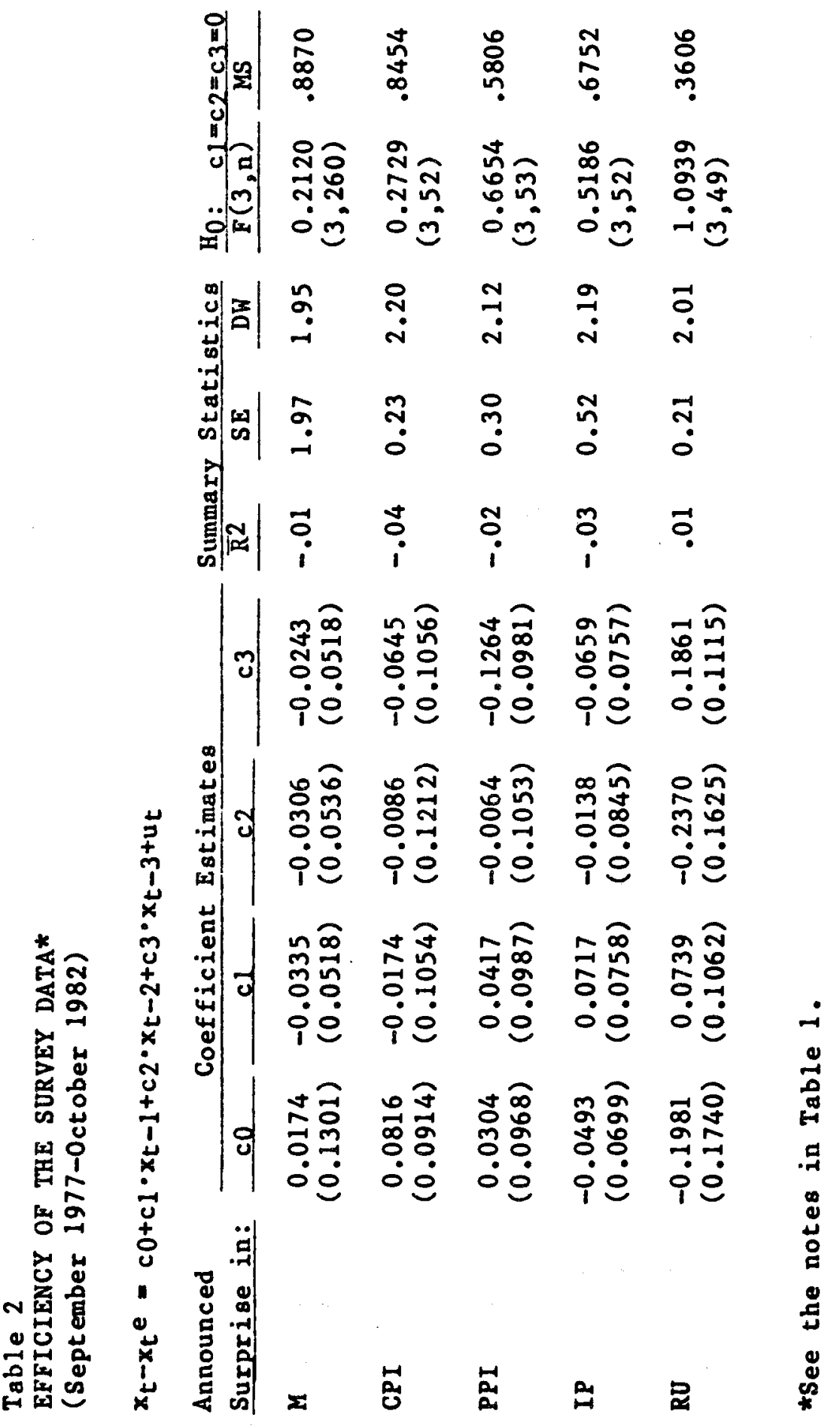


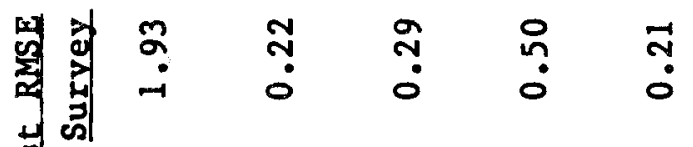

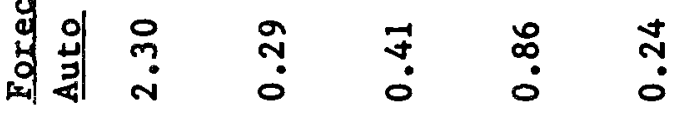

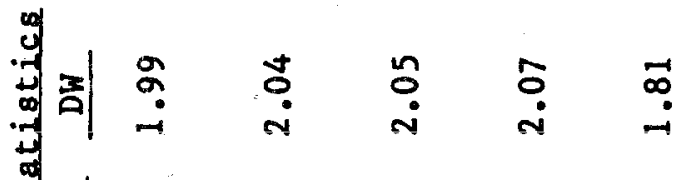

कूँ

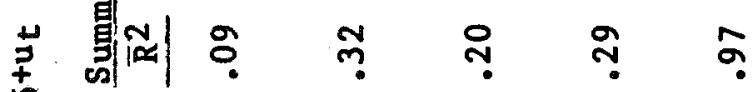

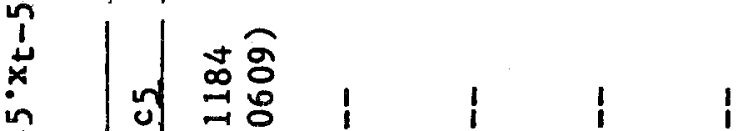

๙

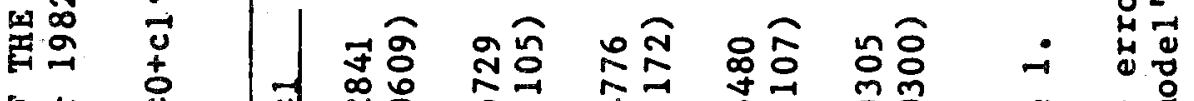

넝 \&

س

范

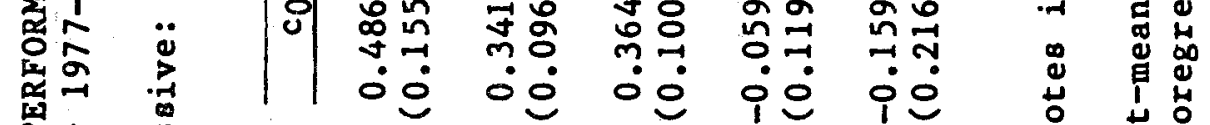

睢

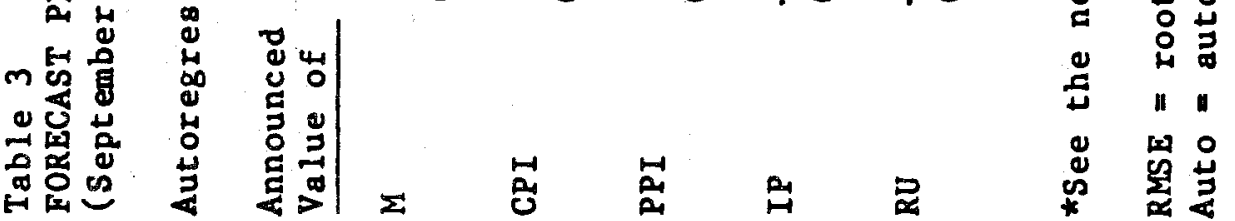




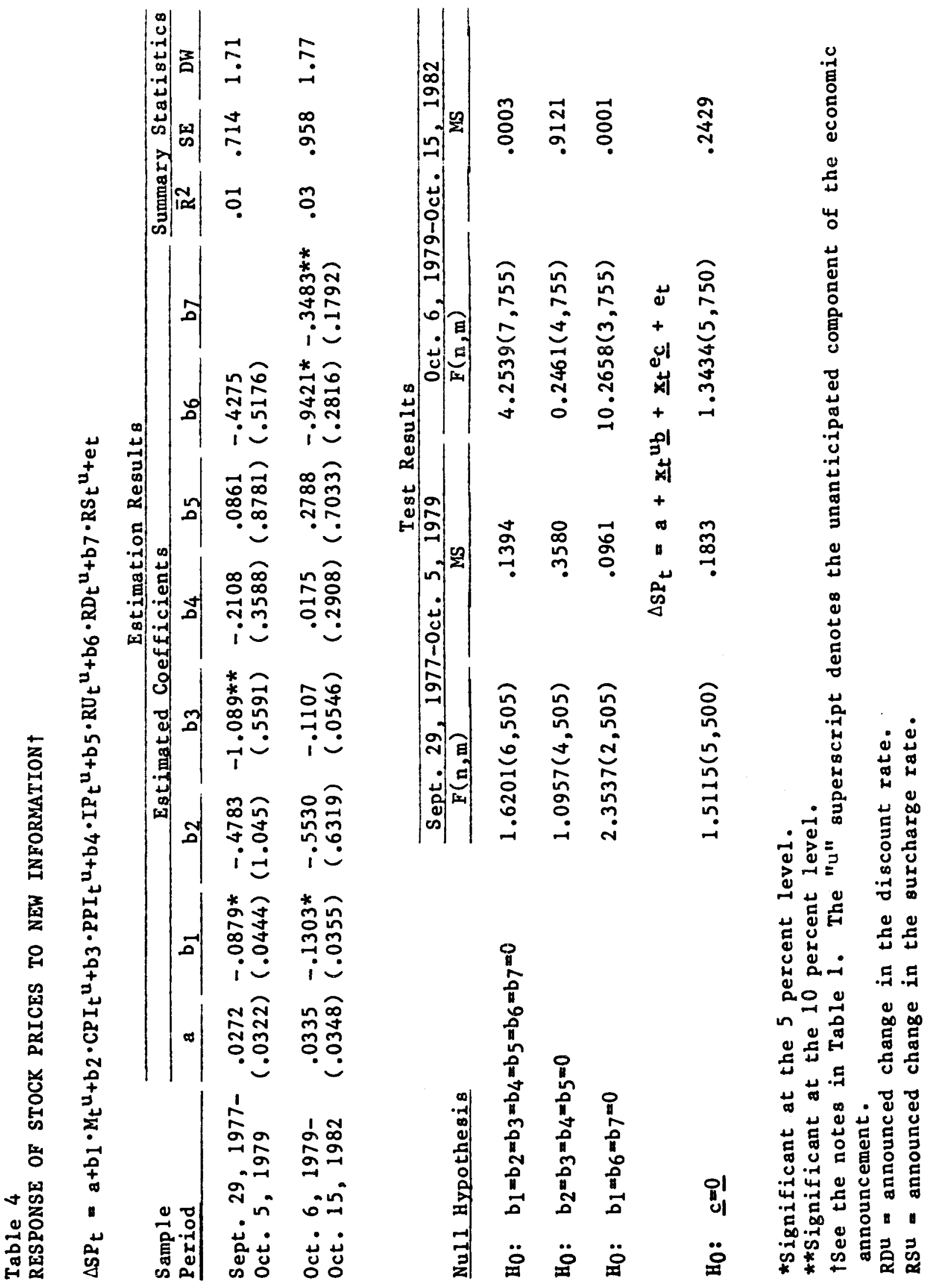




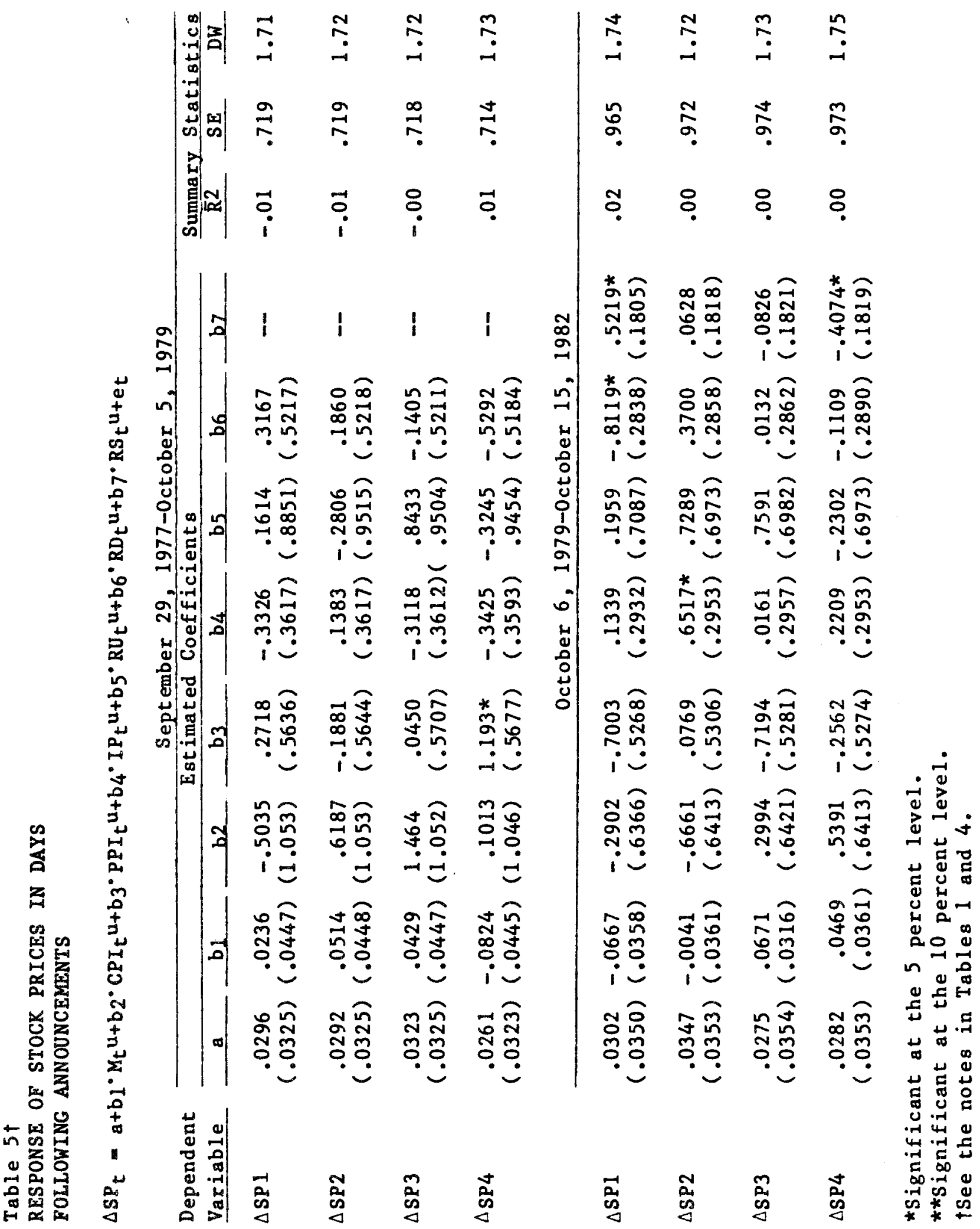




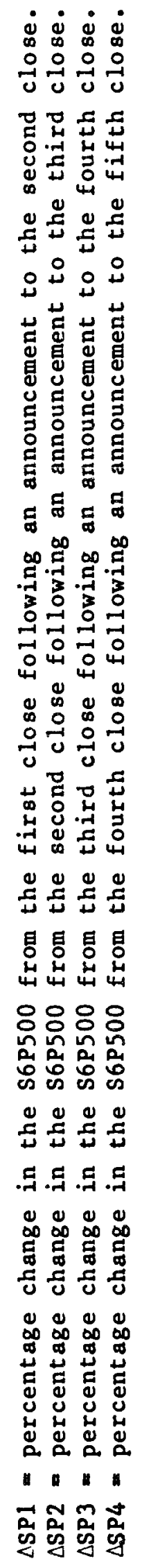




\section{Footnotes}

1/ Waud reports evidence indicating that the market anticipated discount rate declines. As he notes, however, his sample contains discount rate changes which were not simultaneous at all regional Federal Reserve Banks while his analysis focused on New York Federal Reserve Bank discount rate announcements. This may account for the apparent ability of the market to predict discount rate changes.

2/ Using daily stock returns, Schwert reports that CPI surprises have no effects on the day of the announcement, but have significant effects from one to five days following the announcement. His sample period begins in January 1955 and ends in December 1978. Schwert's preferred measure of the expected CPI announcement is estimated from the Treasury bill yield. He also uses a simple autoregressive model analogous to that examined below in Section III, and he reports that the two measures yield the same results.

3/ Berkman (1978) finds similar results to Pearce and Roley using a different measure of unanticipated money stock changes. Niederhoffer (1971) detects a response of stock prices to world events as measured by newspaper headlines. Lloyd-Davies and Caves (1978) report that individual stocks react immediately to the Wall Street Journal recommendations while Arbel and Jaggi (1982) conclude that the market is efficient from their evidence that large stock price movements--their proxy for new information--are not typically followed by abnormal movements.

4) Following Gibbons and Hess (1981), day-of-the-week dummy variables also were included in some of the estimated equations. The significance of these dummies, as well as their effect on the estimation and test results, are discussed in Section IV. 
5/ The discussion in this and subsequent sections is usually in terms of positive surprises. Symmetry is, however, assumed.

6/ The bond market remains open after the money announcement while the stock market has already closed. Thus, interest rates are known to be higher (after a positive money surprise) when the stock market opens on the next business day.

IJ See Schwert (1981) for a careful treatment of the CPI announcement. 8f For discussion of analogous effects of inflation and output on interest rates, see Roley and Troll (1983) and Cornel1 (1983b).

9/ In an earlier study (Pearce and Roley (1983)), the Dow Jones Industrial Average (DJIA) was used to enable the response of stock prices to money announcements to be measured from the market's close to the market's opening. Because of the variety of different types of announcements considered here, and the different times they occur throughout the day, closing prices of a broader index are used in this analysis. 10/ Announced changes in MI-B are analyzed here because of the emphasis placed on Ml-B by Federal Reserve policymakers and market participants. It should also be noted that the Ml-B data for 1981 are not the shift-adjusted Ml-B figures which reflect the introduction of nationwide NOW accounts. While the Federal Reserve's target range was in terms of shift-adjusted M1-B, weekly announced changes were not shift adjusted.

11) We are indebted to Raul A. Nicho, vice president with Money Market Services, for making the survey data available for this project. 12/ To adjust the survey measure, new information was assumed to be reflected by the percentage change in closing stock prices from the day of the survey to the market's latest close prior to the announcement. Announced values of the data were then regressed on the market survey measure and this percentage 
change in stock prices. The fitted values from this regression formed the revised expectation of the economic announcements.

13/ All tests reported in Tables 1, 2, and 3 also were performed separately for the pre- and post-0ctober 1979 periods. The unbiasedness of the survey measure for industrial production announcements cannot be rejected at the 5 percent level in the pre-0ctober 1979 subsample, but this hypothesis can be rejected in the post-0ctober 1979 subsample. The only other difference between the results reported in Table 1 and those for the pre- and postOctober 1979 subsample involves expected values of money announcements. In this case, unbiasedness can be rejected at the 5 percent level of significance in the pre-0ctober 1979 subsample due to a statistically significant constant term.

14/ If relevant variables are excluded from the information set, this test is still valid because the bias will be the same in each autoregression under the null hypothesis. Also note that the single-equation efficiency test specified here is equivalent to testing the hypothesis that data announcement surprises are uncorrelated with previously announced values of the data. For other applications of the efficiency test, see Pesando (1975) and Friedman (1980). 15/ This same result also holds for the pre- and post-0ctober 1979 subsamples .

16f In the pre-October 1979 subsample, the autoregressive model has a somewhat lower root-mean-square error for unemployment rate announcements. Again, the results from the autoregressive model are downward biased. 17) For an analysis of the Livingston inflation survey data, see, for example, Pesando (1975), Mullineaux (1978), and Pearce (1979). For an analysis of the Goldsmith-Nagan interest rate survey data, see Friedman (1980). 
18) The F-statistics were $F(4,501)=2.0455$ and $F(4,751)=1.2998$ with marginal significance levels of .0869 and .2685 for the pre- and post-0ctober 1979 subsamples, respectively. In the pre-October 1979 subsample, the Friday dummy had a positive and statistically significant coefficient, while all other estimated coefficients were insignificantly different from zero. 19f For CPI surprises, Schwert (1981) also found statistically insignificant stock price responses on announcement days, but not on days either before or af ter announcement days.

20 The most significant F-statistic was obtained for the response of stock prices to PPI surprises. In this case, the F-statistic has a value of $F(1,1262)=1.5903$ with a marginal significance level of .2075 .

21 This procedure is analogous to estimating the $\underline{d}_{i}$ coefficients in equation (1). 


\section{References}

Arbel, A. and Jaggi, B. 1982. Market information assimilation related to extreme daily price jumps. Financial Analysts Journal 38 (NovemberDecember): $60-66$.

Berkman, N.G. 1978. On the significance of weekly changes in Ml. New England Economic Review (May/June): 5-22.

Castanias, R.P. 1979. Macroinformation and the variability of stock market prices. Journal of Finance 34 (May): 439-450.

Cornel1, B. 1983a. Money supply announcements and interest rates: another view. Journal of Business 56 (January): 1-23.

Cornel1, B. 1983b. The money supply announcements puzzle: review and interpretation. American Economic Review 83 (September): 644-657.

Fama, E.F., Fisher, L., Jensen, M., and Ro11, R. 1969. The adjustment of stock prices to new information. International Economic Review 10 (February): 1-21.

Feldstein, M. 1980. Inflation and the stock market. American Economic Review 70 (December): 837-847.

Friedman, B.M. 1980. Survey evidence on the 'rationality' of interest rate expectations. Journal of Monetary Economics 6 (October): 453-465.

Gibbons, M.R., and Hess, P.J. 1981. Day of the week effects and asset returns. Journal of Business 54 (October): 579-596.

Grossman, J. 1981. The rationality of money supply expectations and the short-run response of interest rates to monetary surprises. Journal of Money, Credit, and Banking 13 (November): 409-424.

Lloyd-Davies, P. and Caves, M. 1978. Stock prices and the publication of second-hand information. Journal of Business 51 (January): 43-56.

Lombra, R.E., and Torto, R.G. 1977. Discount rate changes and announcement effects. Quarterly Journal of Economics 91 (February): 171-176.

Modigliani, F., and Shiller, R.J. 1973. Inflation, rational expectations and the term structure of interest rates. Economica 40 (February): 12-43.

Mullineaux, D.J. 1978. On testing for rationality: another look at the Livingston price expectations data. Journal of Political Economy 86 (Apri1): 329-336.

Niederhoffer, $\nabla .1971$. The analysis of world events and stock prices. Journal of Business 44 (April): 193-219.

Pesando, J.E. 1975. A note on the rationality of the Livingston price expectations. Journal of Political Economy 83 (August): 849-858. 
Pearce, D.R. 1979. Comparing survey and rational measures of expected inflation. Journat of-Koney,-Gredit, and-Banking 11 (November):

446-456.

Pearce, D.R., and Roley, V.V. 1983. The reaction of stock prices to unanticipated changes in money: a note. Journal-of-Finance 38 (September): 1323-1333.

Roley, V.V. 1982. Weekly money supply announcements and the volatility of short-term interest rates. Federal Reserve Bank of Kansas City, Economic-Review 67 (April): 3-15.

Roley, V.V. 1983. The response of short-term interest rates to weekly money announcements. Journat-of-Koney;-Gredit, and Banking 15 (August): 344-354.

Roley, $\bar{V} \cdot \bar{V}_{.}$, and Troli, $\bar{k}$. 1983. The impact of new economic information on the volatility of short-term interest rates. Federal Reserve Bank of Ransas City, Economic Review 68 (February): 3-15.

Roley, V.V., and Troll, R. 1984. The impact of discount rate changes on market interest rates. Federal Reserve Bank of Kansas City, Economic Review, forthcoming.

Schwert, G.W. 1981. The adjustment of stock prices to information about inflation. Journal-of-Finance 36 (March): 15-29.

Summers, L.H. 1981. Inflation and the valuation of corporate equities. National Bureau of Economic Research Working Paper No. 824 (December).

Urich, T., and Wachtel, P. 1981. Market response to the weekly money supply announcements in the $1970 \mathrm{~s}$. Journat-of-Finance 36 (December): 1063-1972.

Waud, R. 1970. Public interpretation of Federal Reserve discount rate changes: evidence on the 'announcement effect.' Eeonometrica 38 (March): 231-250. 